\title{
Video De-Noising Using Fuzzy Technique
}

\author{
Harneet Kaur*, Neeru Singla \\ Electronics \& Communication, R.I.E.I.T Railmajra, SBS Nagar, India \\ *Corresponding author: harneet758@gmail.com
}

Received March 01, 2013; Revised October 23, 2013; Accepted October 24, 2013

\begin{abstract}
The recent advances in representations of video have achieved outstanding de-noising results, but removing real, structured noise in digital videos remains a challenging problem. In video de-noising the goal of proposed algorithm is to achieve an efficient, adaptive and high-quality video de-noising algorithm. In video and television, noise refers to the random dot pattern that is superimposed on the image as a result of electronic noise. Images taken with both digital cameras and conventional cameras will pick up noise from a variety of sources. This paper deals with performance comparison of Median and Wiener Filters in video de-noising for Gaussian noise and Salt \& Pepper noise. Several examples were conducted to evaluate the performance of the median filter and wiener filter on Gaussian noise and salt and pepper noise.
\end{abstract}

Keywords: frames, salt \& pepper noise, Gaussian noise, wiener filter, median filter

Cite This Article: Harneet Kaur, and Neeru Singla, "Video De-Noising Using Fuzzy Technique.” American Journal of Electrical and Electronic Engineering 1, no. 3 (2013): 46-51. doi: 10.12691/ajeee-1-3-3.

\section{Introduction}

Video cameras are becoming omnipresent. Movies and television have made very close to us. Processing, analyzing and understanding of content present in video are becoming very important. Bulkiness of the data makes the problem of video processing more complex compared to image analysis [1]. However, video processing is not just about processing individual frames/images. Video has lot more information than the isolated images. This comes from the spatial temporal continuity of the data. Many of the different comes with different auxiliary and supplementary information. Thus this video processing and analysis necessitates different classes of algorithm. We explore video processing in the larger context of multimedia and multimodal computing [2]. This processing technique can be: video enhancement, video restoration, video compression, video de-noising.

\section{Video Processing}

\subsection{Video Enhancement}

It refers to accentuation, or sharpening, of image features such as boundaries, or contrast to make a graphic display more useful for display \& analysis. This process does not increase the inherent information content in data. It includes gray level \& contrast manipulation, noise reduction, edge sharpening, filtering, interpolation and magnification, pseudo coloring, and so on [3].

\subsection{Video Restoration}

It is concerned with filtering the observed image to minimize the effect of degradations. Effectiveness of image restoration depends on the extent and accuracy of the knowledge of degradation process as well as on filter design. Image restoration differs from image enhancement in that the latter is concerned with more extraction or accentuation of image features $[3,4]$.

\subsection{Video Compression}

It is concerned with minimizing the no of bits required to represent an image. Application of compression are in broadcast $\mathrm{TV}$, remote sensing via satellite, military communication via aircraft, radar, teleconferencing, facsimile transmission, for educational \& business documents, medical images that arise in computer tomography, magnetic resonance imaging and digital radiology, motion, pictures, satellite images, weather maps, geological surveys and so on [3].

\subsection{Video De-Noising}

Video is a technology of electronically capturing, recording, processing, storing, transmitting and reconstructing a sequence of still images representing scenes in motion. The use of video allows the time dependence to be characterized for these measurements. With today's advances in sensor design, the image/video is relatively clean for high-end digital cameras at low sensitivities, but it remains noisy for low cost cameras at high sensitivities. The problem of removing image noise is still of acute and in fact growing importance with the prevalence of webcams and mobile phone cameras. In general, video data tend to be noisier than single image due to high speed capturing rate of video camera. Interference and static are other form of noise, in the sense that they are unwanted, though not random, which can effect radio and television signal. Video de-noising methods can be divided into: Spatial video de-noising 
methods, where image noise reduction is applied to each frame individually, Temporal video de-noising methods, where noise between frames is reduced \& SpatialTemporal video de-noising methods use a combination of spatial and temporal de-noising. Video signals can be classified [5] as shown in Figure 1.

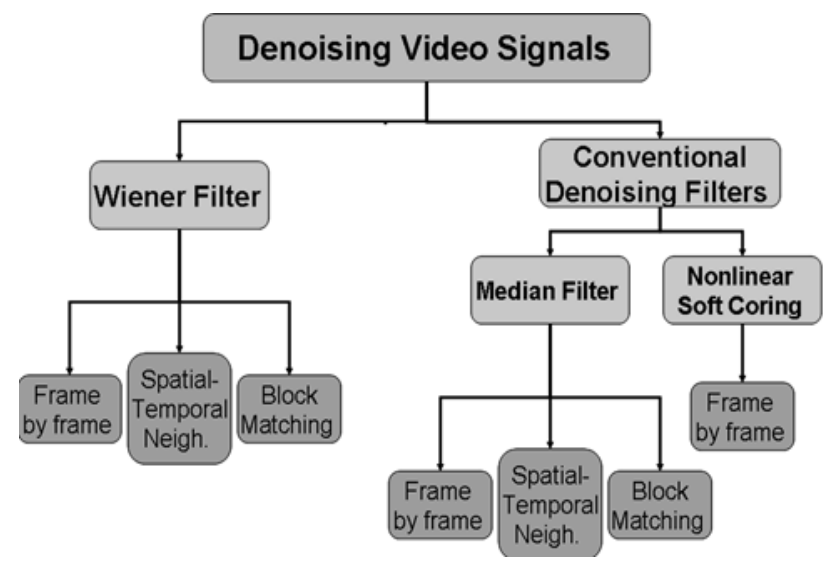

Figure 1. Classification of video signal

The Section 3 has an overview of various types of noise and the discussion is made about the basics of salt \& pepper noise and Gaussian noise. Section 4 introduces with the types of filter used \& In Section 5 the results are experimented. Finally Section 6 has the conclusion of the proposed work.

\section{Noise}

Noise is dominant factor that degrades image quality. Many further uses of these images require that the noise should be (partially) removed. Noise can be of: Salt and pepper noise (impulse noise), Gaussian noise (amplifier noise), Shot noise, Quantization noise.

In salt and pepper noise(sparse light and dark disturbances),pixels in the image are very different in colour or intensity from there surrounding pixel the defining characteristics is that the value of the noisy pixel bears no relation to the colour of surrounding pixel .Generally this type of noise will only effect a small number of image pixels. When viewed, the image contain dark and white dots, hence the term salt and pepper noise. The main challenge in removing salt/pepper noise from binary image is due to the fact that image data as well as the noise share the same small set of values (either 0 or 1 ), which complicates the process of detecting and removing the noise [6].

In Gaussian noise, each pixel in the image will be changed from its original value by usually a small amount. Gaussian noise is statistical noise that has its probability density function equal to that of the normal distribution, which is also known as the Gaussian distribution.

\section{Filters Used to Reduce the Effect of Noise}

Normally filters are used to remove noise from images. Filters are classified into two types: Linear Filters \& Nonlinear Filters.
Linear filters too tend to blur sharp edges, destroy lines and other fine image details, and perform poorly in the presence of signal-dependent noise. With non-linear filters, the noise is removed without any attempts to explicitly identify it.

Nonlinear filters have quite different behavior compared to linear filters. For nonlinear filters, the filter output or response of the filter does not obey the principles outlined earlier, particularly scaling and shift invariance. Moreover, a nonlinear filter can produce results that vary in a non-intuitive manner [7].

The simplest nonlinear filter to consider is the median or rank-order filter. In the median filter, filter output depends on the ordering of input values, usually ranked from smallest to largest or vice versa. A filter support range with an odd number of values is used, making it easy to select the output.

\subsection{Median Filter}

The median filter was one of the most popular nonlinear filters for removing Salt \& Pepper noise. The noise is removed by replacing the window center value by the median value of center neighborhood. The median filter is a robust filter. These are widely used as smoothers for image processing, as well as in signal processing and time series processing. Such noise reduction is a typical pre-processing step to improve the results of later processing (for example, edge detection on an image). Median filtering is a nonlinear process useful in reducing impulsive, or salt and pepper noise. It also useful in preserving edges in an image, while reducing random noise. In this filter, a window slides along the image, and the median intensity value of the pixels within the window becomes the output intensity of the pixel being processed.

A major advantage of the median filter over linear filters is that the median filter can eliminate the effect of input noise values with extremely large magnitudes. (In contrast, linear filters are sensitive to this type of noise that is, the output may be degraded severely by even by a small fraction of anomalous noise values) [8].

\subsection{Wiener Filter}

The goal of the Wiener filter is to filter out noise that has corrupted a signal. It is based on a statistical approach. Typical filters are designed for a desired frequency response. The Wiener filter approaches filtering from a different angle. One is assumed to have knowledge of the spectral properties of the original signal and the noise, and one seeks the LTI filter whose output would come as close to the original signal as possible. Wiener filters are characterized by the following: Assumption: signal and (additive) noise are stationary linear random processes with known spectral characteristics, Requirement: the filter must be physically realizable, i.e. causal (this requirement can be dropped, resulting in a non-causal solution), Performance criteria: minimum mean-square error [9].

\section{Results and Discussion}

To compare the simulation results for video de-noising: Gstennis.avi and Mother.avi are taken. Frames taken: 30 frames/sec, 150 frames $/ 5 \mathrm{sec}$. 
To assess the performance of the wiener and median filter for removal of Salt \& pepper noise and Gaussian noise standard performance indices defined as follows are used:

Peak Signal to Noise Ratio (PSNR): It is measured in Decibel $(\mathrm{dB})$ and for gray scale image it is defined as Eq.1:

$$
\begin{gathered}
P S N R=\left[10 \log _{10} \frac{M A X^{2}}{M S E(F, O)}\right] \\
M S E=\frac{1}{N M} \sum_{i=1}^{N} \sum_{j=1}^{M}\left[O(i, j)-F(i . j)^{2}\right]
\end{gathered}
$$

Where MSE as in Eq.2 is the mean square error between the original and the denoised image (The higher the PSNR in the restored image, the better is its quality), $\mathrm{NM}$ is the size of the video taken, $\mathrm{O}$ is the original size of video, and $\mathrm{F}$ is the restored size. Algorithm used is shown in Figure 2.

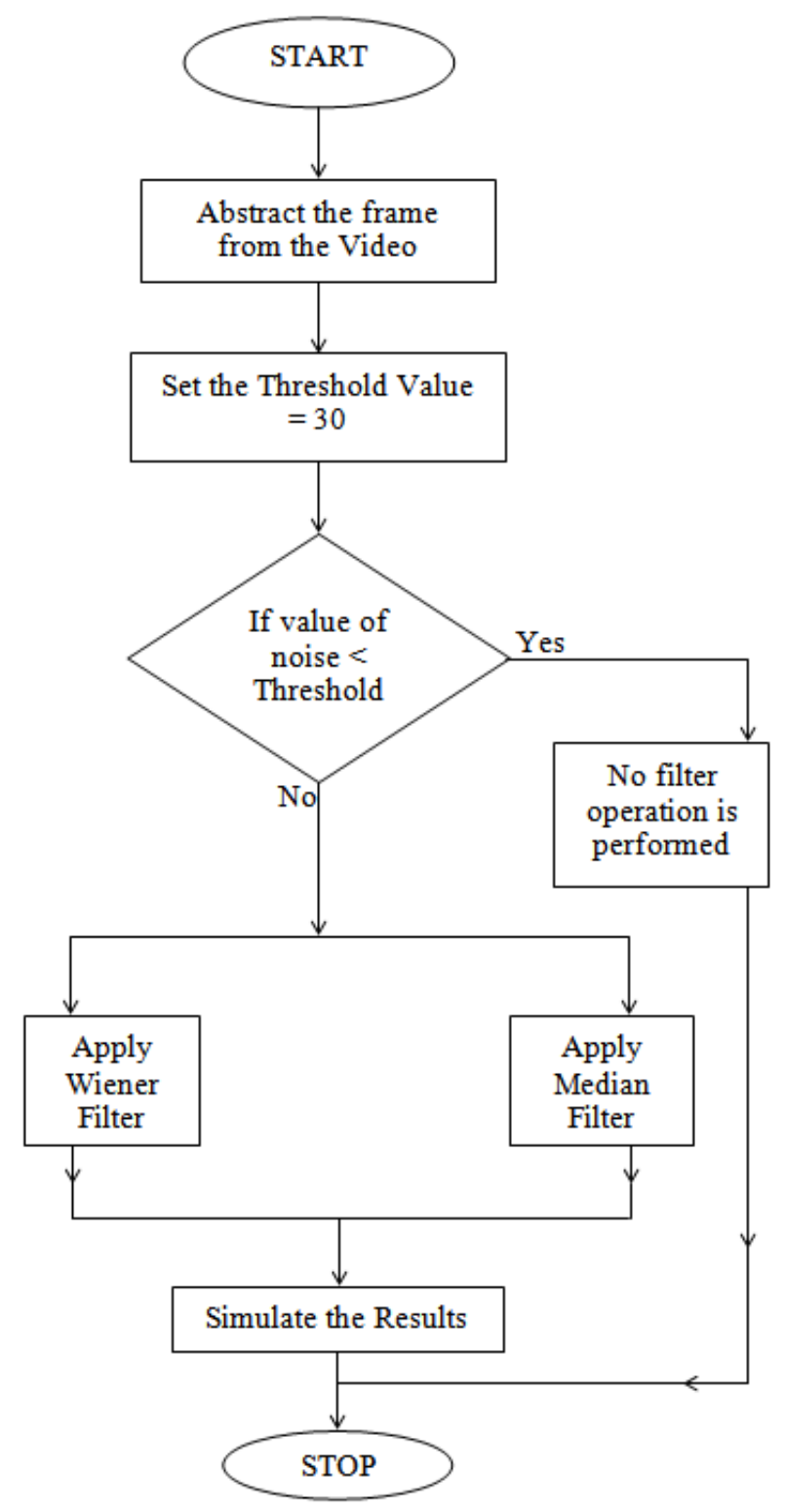

Figure 2. Algorithm of proposed work

Starting from extracting the frame from video, threshold value is set below which noise is ignored and above which we need to reduce or remove that noise here we have considered Gaussian and salt and pepper noise thus wiener filter and median filter is applied and find out which filter is better for which kind of noise. Thus results are simulated. By following the steps as in proposed algorithm, PSNR of Wiener and Median filter is compared as shown in Table 1, Table 2, Table 3, Table 4, Table 5, Table 6, Table 7 and Table 8 and results are concluded.

\subsection{For Gstennis.avi Video}

Table 1. COMPARISON OF PSNR FOR WIENER \& MEDIAN FILTER WITH GAUSSIAN NOISE FOR GSTENNIS VIDEO (1SEC)

\begin{tabular}{|c|c|c|c|}
\hline $\begin{array}{c}\text { FRAME } \\
\text { NUMBER }\end{array}$ & $\begin{array}{c}\text { PSNR(dB) } \\
\text { FOR } \\
\text { MEDIAN } \\
\text { FILTER }\end{array}$ & $\begin{array}{c}\text { PSNR(dB) } \\
\text { FOR } \\
\text { WIENER } \\
\text { FILTER }\end{array}$ & IMPROVEMENT \\
\hline 10 & 30.0868 & 28.5262 & 1.5606 \\
\hline 15 & 31415 & 28.5230 & 1.6185 \\
\hline 20 & 30.0615 & 28.4993 & 1.5622 \\
\hline 25 & 31932 & 28.4803 & 1.7129 \\
\hline 30 & 30.7770 & 28.5882 & 2.1888 \\
\hline
\end{tabular}

Table 2. COMPARISON OF PSNR FOR WIENER \& MEDIAN FILTER WITH SALT \& PEPPER NOISE FOR GSTENNIS VIDEO (1SEC)

\begin{tabular}{|c|c|c|c|}
\hline $\begin{array}{c}\text { FRAME } \\
\text { NUMBER }\end{array}$ & $\begin{array}{c}\text { PSNR(dB) } \\
\text { FOR } \\
\text { MEDIAN } \\
\text { FILTER }\end{array}$ & $\begin{array}{c}\text { PSNR(dB) } \\
\text { FOR } \\
\text { WIENER } \\
\text { FILTER }\end{array}$ & IMPROVEMENT \\
\hline 10 & 32.7509 & 33.3016 & 0.5506 \\
\hline 15 & 32.7223 & 33.3362 & 0.6139 \\
\hline 20 & 32.6497 & 33.3114 & 0.6616 \\
\hline 25 & 31.9865 & 32.5131 & 0.1666 \\
\hline 30 & 32.7710 & 33.4041 & 0.6330 \\
\hline
\end{tabular}

Table 3. COMPARISON OF PSNR FOR WIENER \& MEDIAN FILTER WITH GAUSSIAN NOISE FOR GSTENNIS VIDEO (5SEC)

\begin{tabular}{|c|c|c|c|}
\hline FRAME & $\begin{array}{c}\text { PSNR(dB) } \\
\text { FOR } \\
\text { MEDIAN } \\
\text { FILTER }\end{array}$ & $\begin{array}{c}\text { PSNR(dB) } \\
\text { FOR } \\
\text { WIENER } \\
\text { FILTER }\end{array}$ & IMPROVEMENT \\
\hline 50 & 34.1982 & 34.7568 & 5585 \\
\hline 75 & 33.3743 & 33.4023 & 0.027 \\
\hline 100 & 32.5309 & 32.5874 & 0.056 \\
\hline 125 & 32.6858 & 32.7643 & 0.078 \\
\hline 150 & 32.6562 & 32.5463 & 109 \\
\hline
\end{tabular}


Table 4. COMPARISON OF PSNR FOR WIENER \& MEDIAN FILTER WITH SALT \& PEPPER NOISE FOR GSTENNIS VIDEO (5SEC)

\begin{tabular}{|c|c|c|c|}
\hline $\begin{array}{c}\text { FRAME } \\
\text { NUMBER }\end{array}$ & $\begin{array}{c}\text { PSNR(dB) } \\
\text { FOR MEDIAN } \\
\text { FILTER }\end{array}$ & $\begin{array}{c}\text { PSNR(dB) FOR } \\
\text { WIENER } \\
\text { FILTER }\end{array}$ & IMPROVEMENT \\
\hline 50 & 32.3724 & 28.5153 & 3.8571 \\
\hline 75 & 31.9926 & 28.1724 & 3.8202 \\
\hline 100 & 31.3635 & 28.5803 & 2.7832 \\
\hline 125 & 31.3232 & 28.3141 & 3.0091 \\
\hline 150 & 31.2929 & 27.6240 & 3.6689 \\
\hline
\end{tabular}

\subsection{For Mother.avi Video}

Table 5. COMPARISON OF PSNR FOR WIENER \& MEDIAN FILTER WITH GAUSSIAN NOISE FOR MOTHER VIDEO (1SEC)

\begin{tabular}{|c|c|c|c|}
\hline $\begin{array}{c}\text { FRAME } \\
\text { NUMBER }\end{array}$ & $\begin{array}{c}\text { PSNR(dB) FOR } \\
\text { MEDIAN } \\
\text { FILTER }\end{array}$ & $\begin{array}{c}\text { PSNR(dB) } \\
\text { FOR WIENER } \\
\text { FILTER }\end{array}$ & IMPROVEMENT \\
\hline 10 & 36.2027 & 37.6941 & 1.4914 \\
\hline 15 & 36.2995 & 37.7706 & 1.6599 \\
\hline 20 & 36.1107 & 37.5332 & 1.4225 \\
\hline 25 & 36.3037 & 37.7695 & 1.4658 \\
\hline 30 & 36.1167 & 37.6398 & 1.5231 \\
\hline
\end{tabular}

Table 6. COMPARISON OF PSNR FOR WIENER \& MEDIAN FILTER WITH SALT \& PEPPER NOISE FOR MOTHER VIDEO (1SEC)

\begin{tabular}{|c|c|c|c|}
\hline $\begin{array}{c}\text { FRAME } \\
\text { NUMBER }\end{array}$ & $\begin{array}{c}\text { PSNR(dB) } \\
\text { FOR MEDIAN } \\
\text { FILTER }\end{array}$ & $\begin{array}{c}\text { PSNR(dB) } \\
\text { FOR WIENER } \\
\text { FILTER }\end{array}$ & IMPROVEMENT \\
\hline 10 & 33.0285 & 29.0087 & 4.0198 \\
\hline 15 & 33.1346 & 29.3539 & 3.7807 \\
\hline 20 & 33.1529 & 29.2676 & 3.8853 \\
\hline 25 & 32.9945 & 29.2120 & 3.7825 \\
\hline 30 & 33.0154 & 29.2068 & 3.8086 \\
\hline
\end{tabular}

Table 7. COMPARISON OF PSNR FOR WIENER \& MEDIAN FILTER WITH GAUSSIAN NOISE FOR MOTHER VIDEO (5SEC)

\begin{tabular}{|c|c|c|c|}
\hline $\begin{array}{c}\text { FRAME } \\
\text { NUMBER }\end{array}$ & $\begin{array}{c}\text { PSNR(dB) FOR } \\
\text { MEDIAN } \\
\text { FILTER }\end{array}$ & $\begin{array}{c}\text { PSNR(dB) FOR } \\
\text { WIENER } \\
\text { FILTER }\end{array}$ & IMPROVEMENT \\
\hline 50 & 34.7775 & 36.1986 & 1.4211 \\
\hline 75 & 34.5834 & 36.0306 & 1.4472 \\
\hline 100 & 34.6229 & 35.6630 & 1.0401 \\
\hline 125 & 34.8153 & 36.0390 & 1.2237 \\
\hline 150 & 34.7002 & 36.1743 & 1.4741 \\
\hline
\end{tabular}

Table 8. COMPARISON OF PSNR FOR WIENER \& MEDIAN FILTER WITH SALT \& PEPPER NOISE FOR MOTHER VIDEO (5SEC)

\begin{tabular}{|c|c|c|c|}
\hline $\begin{array}{c}\text { FRAME } \\
\text { NUMBER }\end{array}$ & $\begin{array}{c}\text { PSNR(dB) } \\
\text { FOR MEDIAN } \\
\text { FILTER }\end{array}$ & $\begin{array}{c}\text { PSNR FOR } \\
\text { WIENER } \\
\text { FILTER }\end{array}$ & IMPROVEMENT \\
\hline 50 & 32.8551 & 29.0245 & 3.8306 \\
\hline 75 & 32.8713 & 29.4641 & 3.4072 \\
\hline 100 & 32.5371 & 29.3581 & 3.179 \\
\hline 125 & 32.7031 & 29.3859 & 3.3172 \\
\hline 150 & 33.0780 & 29.4611 & 3.6169 \\
\hline
\end{tabular}

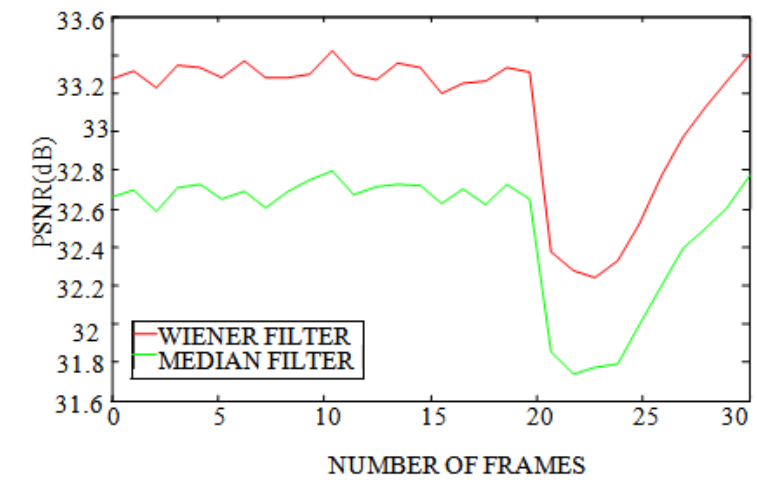

Figure 3. COMPARISON OF WIENER AND MEDIAN FILTER WITH GAUSSIAN NOISE FOR GSTENNIS VIDEO (1SEC)

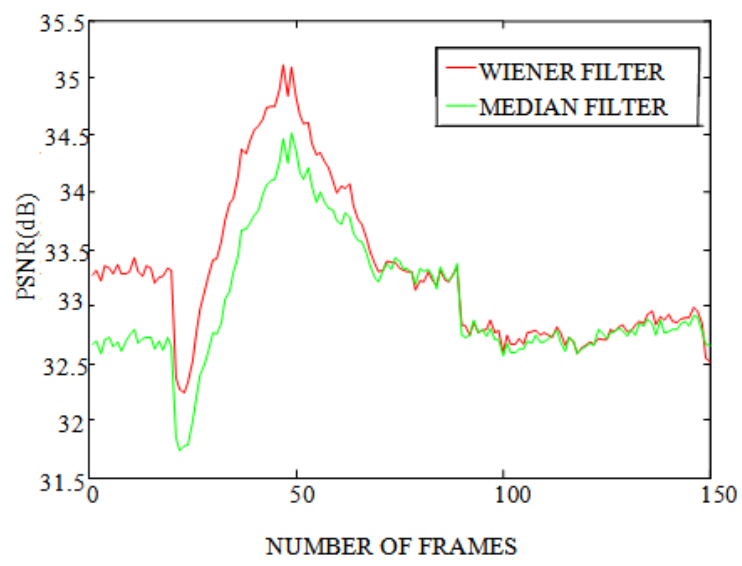

Figure 4. COMPARISON OF WIENER AND MEDIAN FILTER WITH GAUSSIAN NOISE FOR GSTENNIS VIDEO (5SEC)

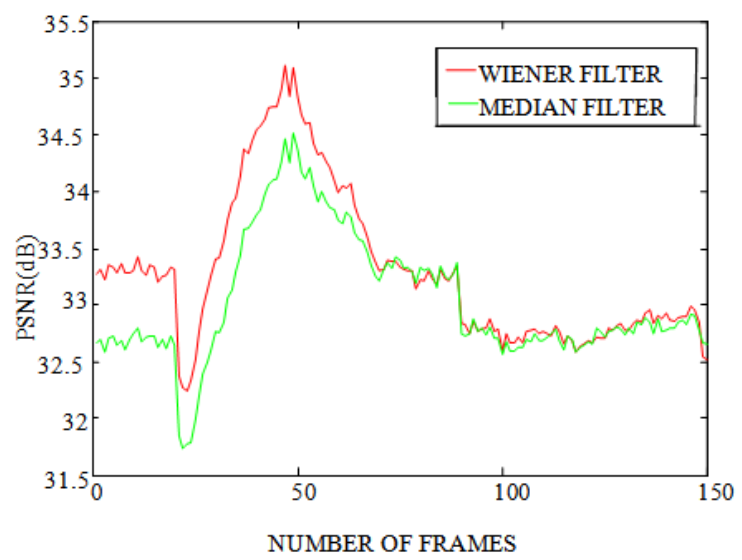

Figure 5. COMPARISON OF WIENER AND MEDIAN FILTER WITH SALT \& PEPPER NOISE FOR GSTENNIS VIDEO (1SEC) 


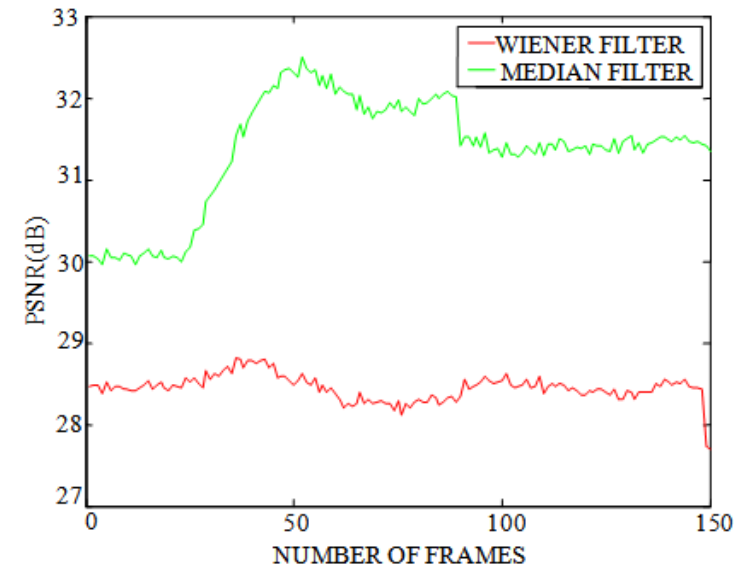

Figure 6. COMPARISON OF WIENER AND MEDIAN FILTER WITH SALT \& PEPPER NOISE FOR GSTENNIS VIDEO (5SEC)

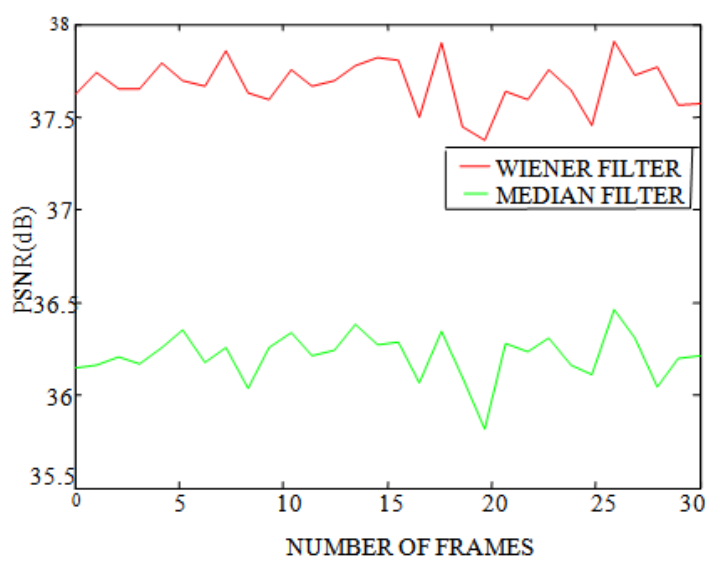

Figure 7. COMPARISON OF WIENER AND MEDIAN FILTER WITH GAUSSIAN NOISE FOR MOTHER VIDEO (1SEC)

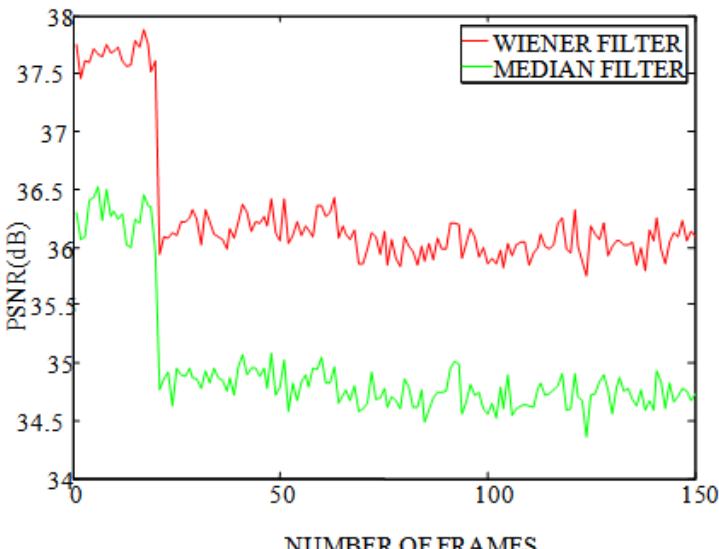

Figure 8. COMPARISON OF WIENER AND MEDIAN FILTER WITH GUASSIAN NOISE FOR MOTHER VIDEO (5SEC)

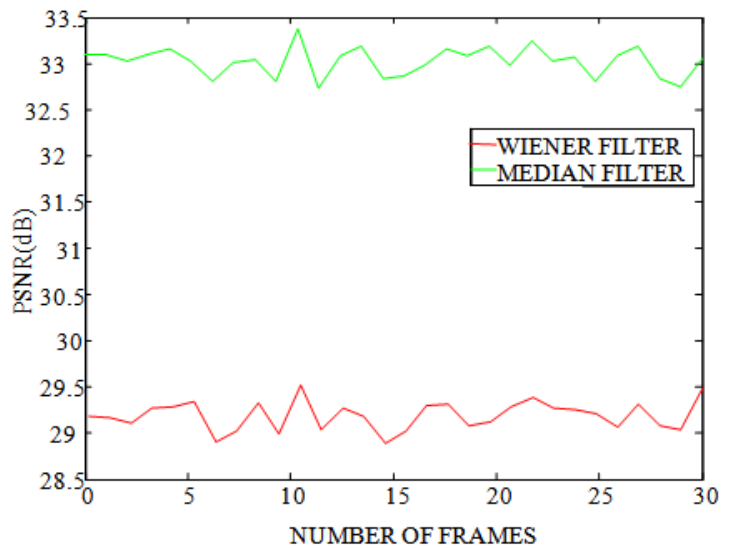

Figure 9. COMPARISON OF WIENER AND MEDIAN FILTER WITH SALT \& PEPPER NOISE FOR MOTHER VIDEO (1SEC)

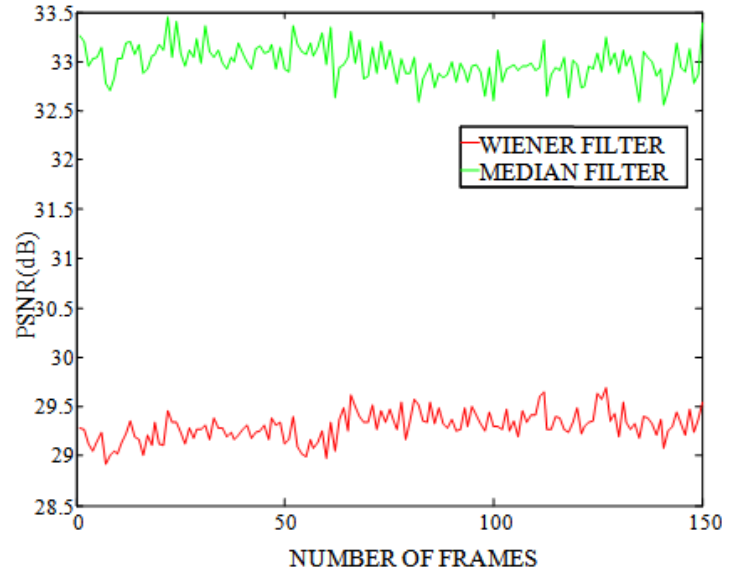

Figure 10. COMPARISON OF WIENER AND MEDIAN FILTER WITH SALT \& PEPPER NOISE FOR MOTHER VIDEO (5SEC)

\subsection{Graphics}

The results shown in graphics proves that Wiener filter is better for Salt and Pepper noise and Median filter is better for Gaussian noise as shown in Figure 3, Figure 4, Figure 5, Figure 6, Figure 7, Figure 8, Figure 9, Figure 10.

\subsection{Comparison of Figures for Gstennis.avi Video}

Figure 11 shows the original frame of Gstennis video taken, Figure 12 show the noisy frame \& Figure 13 show the filtered frame. Similarly Figure 14 show the original frame of mother video taken, Figure 15 show the noisy frame \& Figure 16 show the filtered frame after applying algorithm.

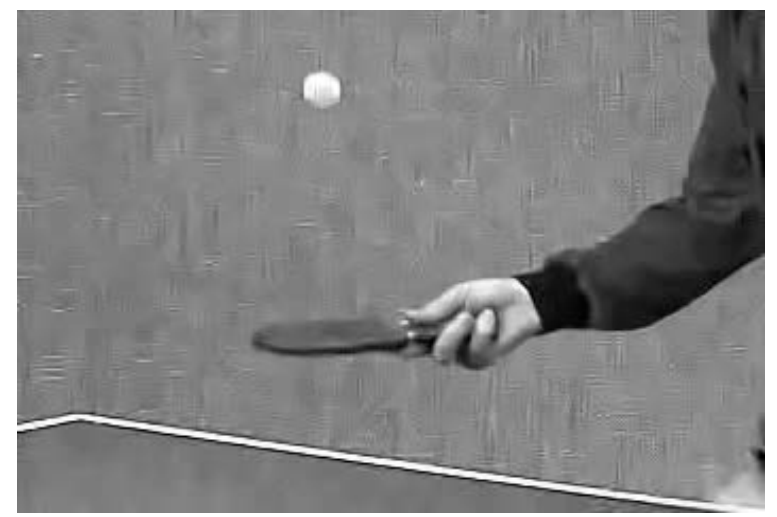

Figure 11. ORIGINAL FRAME

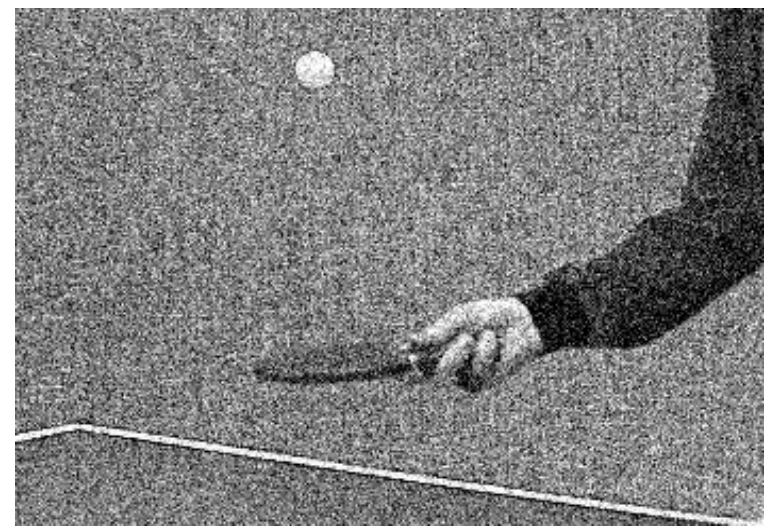

Figure 12. NOISY FRAME 


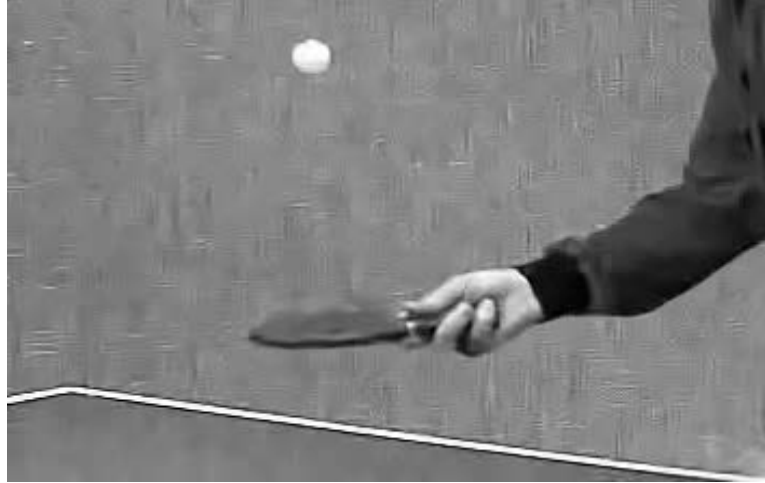

Figure 13. FILTERED FRAME

\subsection{Comparison of Figures for Mother.avi Video}

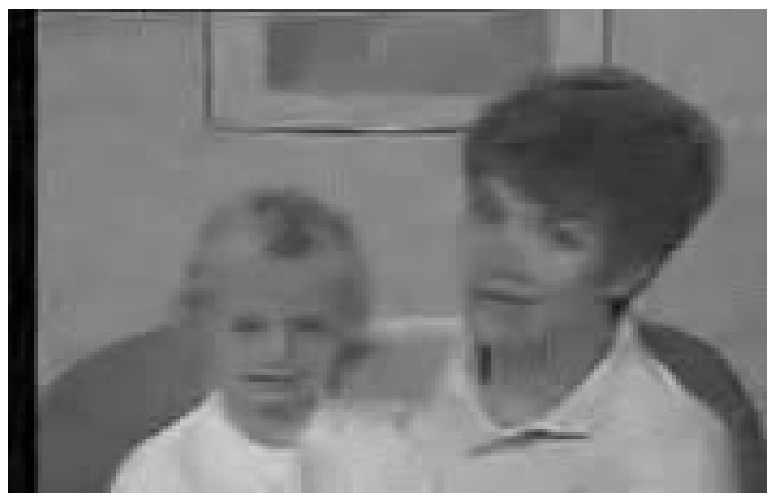

Figure 14. ORIGINAL FRAME

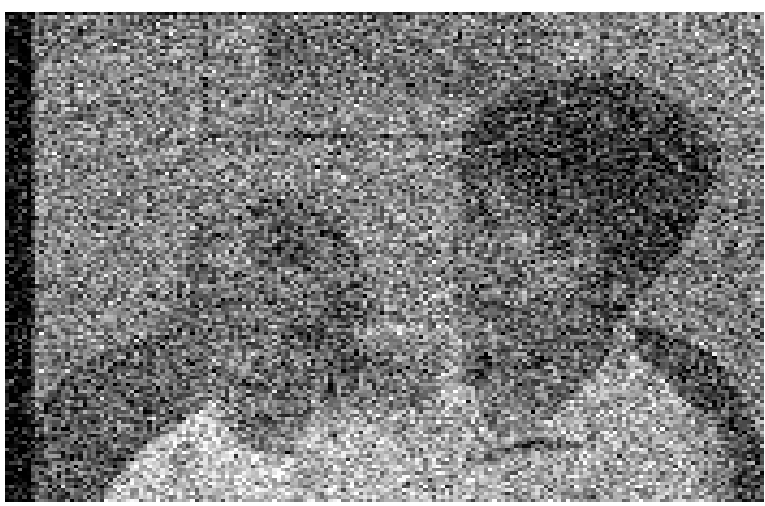

Figure 15. NOISY FRAME

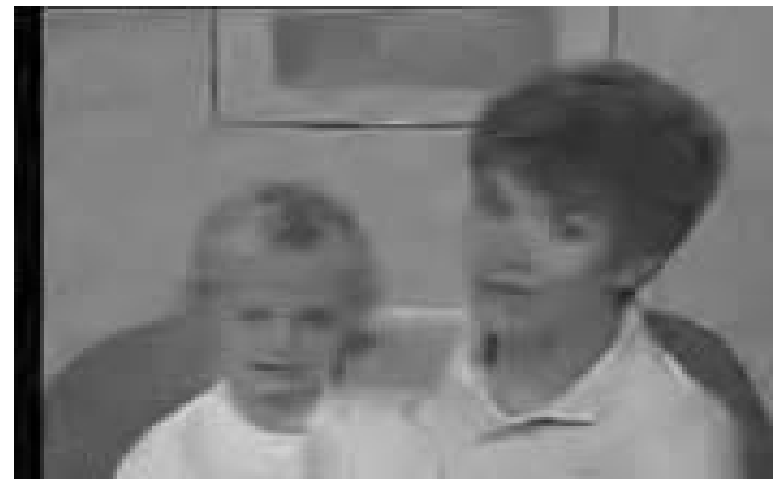

Figure 16. FILTERED FRAME

\section{Conclusion}

This paper attempts to remove Salt \& pepper noise and Gaussian noise using median filter and wiener filter from videos taken. The performance of the median filter and wiener filter are compared and analyzed according to PSNR value. From the performance analyses the median filter gives better results for filtering salt and pepper noise while wiener filter proves to be better for reducing Gaussian noise.

\section{References}

[1] Video Processing Centre for Visual Information Technology: IIIT Hyderabad Publications

$<$ http://web2py.iiit.ac.in/research_centres/De fault/view_area/216>

[2] Gonzalez R.C., Digital Image Processing, R.E. Woods, Prentice Hall, 2008.

[3] http://www.answers.com/topic/image-processing.

[4] Shankar K Pramod, Jawahar C.V. and Zisserman Andrew "Subtitle-free Movie to Script Alignment" in Proceedings of British Machine Vision Conference (BMVC 09), IIIT Hyderabad Publications, 7-10 September, 2009, London, UK.

[5] Oke Alice, Omidiora Elijah, Fakolujo Olaosebikan, Falohun Adeleye, Olabiyisi "Effect of Modified Wiener Algorithm on Noise Models" International Journal of Engineering and Technology (IJET) - 2(8), August, 2012.

[6] Maheswari D., "Noise Removal in Compound Image using Median filter" (IJCSE) International Journal on Computer Science and Engineering, 2(4), 1359-1362, Jul.2010.

[7] Balster, E.j. "Combined Spatial and Temporal Domain Wavelet Shrinkage Algorithm for Video Denoising" circuits and Systems for video Technology IEEE Transaction, 16(2), 220-230, Feb.2006.

[8] Dabovkostadin, Foi Alessandro and Egiazarian Karen "Video Denoising by Sparse 3D Transform-domain Collaborative Filtering" $15^{\text {th }}$ European Signal Processing conference (EUSIPCO 2007), EURASIP journals,145-147, September 3-7,2007, Poznam, Poland.

[9] Patidar Pawan, Gupta Manoj, Srivastava Sumit, Kumar Nagawat Ashok "Image De-noising by Various Filters for Different Noise" International Journal of Computer Applications, 9(4), November 2010. 